\title{
Effect of Continuous Nursing on Nursing Effect, Quality of Life and Satisfaction of Children with Pneumonia
}

\author{
YANAN LIU, H. REN', JING GUO AND DAN SU* \\ Department of Pediatric Internal Medicine, ${ }^{1}$ Department of Rehabilitation Medicine, Hebei Hengshui People's Hospital, Hebei \\ Hengshui 053000, P.R. China
}

Liu et al.: Effect of Continuous Nursing on Children with Pneumonia

\begin{abstract}
To explore the effect of continuous nursing intervention on children with pneumonia, survival status and nurse-patient relationship, 90 patients with paediatric pneumonia admitted to the Hebei Hengshui People's Hospital from May 2017 to June 20, 2017 were divided into the regular group and the continuous group according to the order of admission. Each group had 45 children. The routine group received general care and the continuity group received continuous care and compared with the previous group to observe the correlation between the nursing effect, clinical symptom improvement time, quality of life, satisfaction and complications of the two groups. The probability of effectiveness in the continuous group was $95.55 \%$, which is higher than the other group's $75.55 \%$. The two groups were meaningful $\left(X^{2}=4.094\right.$, $p<0.05)$; the duration of body temperature decline in the continuous group $(1.75 \pm 0.65)$, cough remission time (4.24 \pm 1.12$)$, lung rales remission time (4.15 \pm 0.89$)$ and shortness of breath relief $(2.65 \pm 0.65)$ were less than the routine group temperature drop time $(2.85 \pm 0.95)$, cough relief time $(5.95 \pm 1.85)$, lung rales remission time (5.68 \pm 1.25$)$ and shortness of breath relief $(3.45 \pm 0.75)$. The time changes in the 2 groups were increased $(p<0.05)$; before the nursing, the living conditions of the 2 groups were small $(p>0.05)$. After the nursing, the above factors were increased in both groups $(p<0.05)$, and the continuous group improved better $(p<0.05)$. The satisfaction degree of the two groups was $41(91.11 \%), 33(73.33 \%)$, the difference between the 2 groups was large $(p<0.05)$; the side effects during the 2 groups of care 8.89, $26.67 \%$; the two groups had a change $(p<0.05)$. Continuous care helps children with pneumonia to improve disease, reduce the time of pain, reduce medical disputes, reduce heart muscle and lung failure, and is worthy of application.
\end{abstract}

Key words: Pneumonia, continuous care, effect, satisfaction, complications

Pneumonia is a common clinical disease. Children's body defense ability is weak, external bacteria and viruses enter the body, resulting in a series of common clinical symptoms such as fever and dyspnea ${ }^{[1]}$. Because of the incomplete development of organs and the narrow lumen of organs in children with pneumonia, unreasonable treatment will aggravate the condition and even increase the probability of death ${ }^{[2]}$. The reference shows that there are many causes of pneumonia, such as lack of nutrition and seasonal alternation. According to big data, about 350000 children die of pneumonia annually in China. With the changing times, it is required that the nursing mode should also keep pace with the times to improve the condition of children with pneumonia ${ }^{[3]}$. Continuous nursing is a new type of nursing mode based on scientific theory, which changes the traditional model of stopping nursing after discharge. By designing a series of nursing programs, targeted nursing methods can be carried out for patients at different places ${ }^{[4]}$. Continuous nursing in hospital can guide patients to strengthen the treatment effect, reduce the occurrence of dangerous accidents and improve the rehabilitation ability and prognosis of children through continuous follow-up such as discharge guidance ${ }^{[5]}$. Continuous post discharge nursing is a part of the whole nursing plan, which can avoid the aggravation of the disease after discharge, reduce the economic burden of patients, and improve the quality of life ${ }^{[6]}$. However, there are only a few reports on continuous nursing in China, so this paper evaluated the effect of continuous nursing on the nursing effect, quality of life and satisfaction of children with pneumonia.

From May 2017 to June 2019, 90 children with pneumonia in the Hebei Hengshui People's Hospital 
hospital were divided into 2 groups. The admission number was the regular group and the double number was the continuous group, with 45 cases in each group. The general data of the 2 groups were comparable ( $p>0.05)$, as shown in Table 1. This study was approved by the ethics committee of our hospital.

Inclusion criteria were, in line with the diagnostic criteria for pneumonia in children ${ }^{[7]}$, fever and other phenomena and X-ray detection of lung shadow. The exclusion criteria included those who do not cooperate with the treatment; those who have cognitive mental disease and organ disease; and those who have incomplete clinical data.

General nursing care was to keep the inpatient clean and ventilated in time, test the children's life characteristics, ensure enough rest and keep the amount of daily activities. While, continuous nursing method focuses on the long-term care of children. On the basis of the routine group, the patients are continued to be given daily care for a certain period after operation. The nursing contents are as follows.

Diet guidance was provided to children with pneumonia and fever, which included proper drinking water and good eating habits should be established, mainly including protein, vegetables and vitamins, so as to ensure adequate nutrition. However, it is necessary to prevent breathing difficulties caused by excessive eating, mainly focusing on less food and more number of meals and to keep eating in the sleeping position, with light and slow movements, so as to reduce the occurrence of choking.

Respiratory tract care was provided which is as follows, check whether there is secretion in the throat of the child in time, and inform the child or the family member the correct method of sputum discharge, guide the parents to gently pat the child for sputum discharge, and use atomization to help sputum discharge if the sputum discharge is not smooth.

Psychological guidance was provided, to explain the knowledge and precautions of children's pneumonia to their families, reduce the occurrence of prolonged illness due to unclear family living conditions, because of emotional instability caused by physical discomfort of children with pneumonia, it is easy to cry, the nursing staff combined with parents patiently care, divert attention, help to establish a good state and encourage treatment.

Discharge nursing guidance included, impart knowledge to understand the disease and precautions for the children's family members and continue the eating habits followed in the hospital, such as eat less and eat more times, supplement protein, and improve the children's body function. At the same time of sufficient rest, pay attention to the weather and indoor air flow and carry out appropriate outdoor sports. However, in autumn and winter cold season, avoid the crowd to reduce infection.

According to the curative effect standard for evaluation of children's pneumonia ${ }^{[8]}$, significant effect means the clinical symptoms and phenomena are all relieved and $\mathrm{X}$-ray examination shows no inflammatory reaction; effective means the above clinical phenomena are partially eliminated, and X-ray examination shows partial inflammation reduction and ineffective is when the above symptoms have no change or aggravation.

The clinical symptom relief time of patients in routine group and continuous group after nursing was recorded, including fever and dyspnoea. Before and after nursing, children in the routine group and the continuous group were scored on their quality of life. From multiple perspectives, psychological, physiological and so on, there were 4 points in total. Points 1-4 respectively indicated excellent, good, general and poor. The higher the score, the worse the quality of life.

All patients and their families used self-designed satisfaction scale, including 6 factors, a total of 6 points, 0-2- dissatisfaction, 3- basic satisfaction, 4- satisfaction, satisfaction (\%): satisfaction+basic satisfaction/number of patients $\times 100$. The complications of the routine group and the continuous group during the nursing period were statistically analysed, including sepsis, pneumothorax and heart failure. SPSS22.0 software was used to analyse the correlation between the routine group and the continuous group. The calculated results

TABLE 1: GENERAL INFORMATION

\begin{tabular}{|c|c|c|c|c|c|}
\hline \multirow{2}{*}{ Group } & \multicolumn{2}{|c|}{ Sex } & \multirow{2}{*}{ Age $(y)$} & \multirow{2}{*}{ Temperature $\left({ }^{\circ}\right)$} & \multirow{2}{*}{ Course of disease $(d)$} \\
\hline & Man & Woman & & & \\
\hline Routine group & 25 & 20 & $5.46 \pm 1.21$ & $39.5 \pm 0.40$ & $2.95 \pm 1.40$ \\
\hline Continuity group & 23 & 22 & $5.72 \pm 1.15$ & $39.4 \pm 0.50$ & $2.90 \pm 1.50$ \\
\hline $\mathrm{X}^{2} / \mathrm{t}$ & \multicolumn{2}{|c|}{0.179} & 1.045 & 1.048 & 0.164 \\
\hline$P$ & \multicolumn{2}{|c|}{0.672} & 0.299 & 0.298 & 0.871 \\
\hline
\end{tabular}

November-December 2019

Indian Journal of Pharmaceutical Sciences 74 
were indicated by $\chi 2$ or $t$ test, $\mathrm{p}<0.05$ for the difference. The effective probability of the continuity group is 95.55 $\%$, significantly higher than that of the conventional group (75.55\%). The comparison between the 2 groups is significant $\left(\mathrm{x}^{2}=4.094, \mathrm{p}<0.05\right)$, as shown in Table 2 .

The duration of hypothermia (1.75 \pm 0.65$)$, cough remission $(4.24 \pm 1.12)$, rale remission $(4.15 \pm 0.89)$ and shortness of breath remission $(2.65 \pm 0.65)$ in the continuous group were significantly $(p<0.05)$ shorter than those in the routine group's duration of hypothermia (2.85 \pm 0.95$)$, cough remission (5.95 \pm 1.85 ), rale remission $(5.68 \pm 1.25)$ and shortness of breath remission (3.45 \pm 0.75$)$, as shown in Table 3 .

Before nursing, the difference of quality of life between the routine group and the continuous group was small ( $p>0.05$, Table 4). After nursing, the 2 groups showed significant improvement $(\mathrm{p}<0.05)$. The improvement of the continuous group was even better than that of the routine group $(\mathrm{p}<0.05)$. The nursing satisfaction of routine group and continuous group were, 33 (73.33\%) and $41(91.11 \%)$, respectively. The satisfaction of continuous group was significantly higher than that of routine group as shown in Table 5. The incidence of total complications in the continuous group was $8.89 \%$, which was significantly $(\mathrm{p}<0.05)$ lower than that in the routine group $(26.67 \%)$ as shown in Table 6.

Pneumonia is a kind of respiratory system disease, which can be divided into mild and severe. When the disease progresses rapidly and is not controlled in time, it will be accompanied with other symptoms, such as heart and respiratory failure. The incidence of pneumonia in children is high, it is seasonal and increases when the weather changes greatly. Some studies have pointed out that when external bacteria invade the body, such as Mycoplasma, they often induce asthma, so timely treatment and care to prevent other complications are of great significance in the treatment of children with pneumonia ${ }^{[9]}$.

This study suggested that the effective rate of nursing in the continuous group is higher than that in the

TABLE 2: CLINICAL EFFICACY [n/(\%)]

\begin{tabular}{lccccc}
\hline Group & $\mathrm{n}$ & Markedly effective & Effective & Not effective & Effective rate \\
\hline Routine group & 45 & $24(53.33)$ & $10(22.22)$ & $11(24.44)$ & $34(75.55)$ \\
Continuity group & 45 & $31(68.69)$ & $12(26.67)$ & $2(4.44)$ & $42(95.55)^{*}$ \\
$\mathrm{X}^{2} / \mathrm{t}$ & & 1.934 & 0.405 & 10.15 & 4.094 \\
$\mathrm{P}$ & & 0.164 & 0.245 & 0.002 & 0.043 \\
\hline
\end{tabular}

*Compared with routine group $\mathrm{p}<0.05$

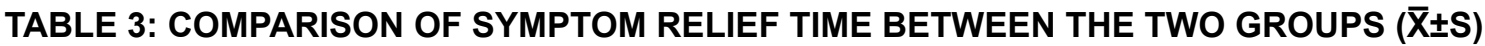

\begin{tabular}{lccccc}
\hline Group & $\mathbf{n}$ & $\begin{array}{c}\text { Hypothermia time } \\
(\mathbf{d})\end{array}$ & $\begin{array}{c}\text { Cough relief time } \\
(\mathbf{d})\end{array}$ & $\begin{array}{c}\text { Lung rale remission } \\
\text { time (d) }\end{array}$ & $\begin{array}{c}\text { Shortness of breath } \\
\text { relief time (d) }\end{array}$ \\
\hline Routine group & 45 & $2.85 \pm 0.95$ & $5.95 \pm 1.85$ & $5.68 \pm 1.25$ & $3.45 \pm 0.75$ \\
Continuity group & 45 & $1.75 \pm 0.65^{*}$ & $4.24 \pm 1.1^{2 *}$ & $4.15 \pm 0.89^{*}$ & $2.65 \pm 0.65^{*}$ \\
$\mathrm{t}$ & & 6.410 & 5.304 & 6.689 & 5.407 \\
$\mathrm{P}$ & & $<0.001$ & $<0.001$ & $<0.001$ & $<0.001$ \\
\hline
\end{tabular}

*Compared with routine group $\mathrm{p}<0.05$

TABLE 4: COMPARISON OF QUALITY OF LIFE BETWEEN TWO GROUPS ( $\bar{X} \pm S)$

\begin{tabular}{lccccc}
\hline Group & $\mathbf{n}$ & Before nursing & After nursing & $\mathrm{t}$ & $\mathrm{P}$ \\
\hline Routine group & 45 & $116.56 \pm 12.04$ & $110.13 \pm 10.32^{\#}$ & 2.72 & 0.008 \\
Continuity group & 45 & $117.09 \pm 12.11$ & $65.89 \pm 6.23^{* \#}$ & 25.22 & $<0.001$ \\
$\mathrm{t}$ & & 0.208 & 24.62 & \\
$\mathrm{P}$ & & 0.835 & $<0.001$ & \\
\hline
\end{tabular}

*Compared with routine group; \#Compared with pre nursing $p<0.05$

TABLE 5: COMPARISON OF NURSING SATISFACTION [N/(\%)]

\begin{tabular}{lccccc}
\hline Group & $\mathbf{n}$ & Satisfaction & Basic satisfaction & Dissatisfaction & Satisfaction degree \\
\hline Routine group & 45 & $15(33.33)$ & $18(40.00)$ & $12(26.67)$ & $33(73.33)$ \\
Continuity & 45 & $22(48.89)$ & $19(42.22)$ & $4(8.89)$ & $41(91.11)^{*}$ \\
group & & & & 3.993 \\
$X^{2}$ & & & & 0.046 \\
P & & & & \\
\hline
\end{tabular}


TABLE 6: COMPARISON OF COMPLICATIONS BETWEEN THE TWO GROUPS [N/(\%)]

\begin{tabular}{|c|c|c|c|c|c|c|c|c|}
\hline Group & $\mathrm{n}$ & Emphysema & $\begin{array}{l}\text { Respiratory } \\
\text { failure }\end{array}$ & Pneumothorax & $\begin{array}{l}\text { Heart } \\
\text { failure }\end{array}$ & $\begin{array}{c}\text { Hypoxic } \\
\text { encephalopathy }\end{array}$ & $\begin{array}{l}\text { Toxic } \\
\text { shock }\end{array}$ & $\begin{array}{c}\text { Total } \\
\text { incidence rate }\end{array}$ \\
\hline $\begin{array}{l}\text { Routine } \\
\text { group }\end{array}$ & 45 & $3(6.67)$ & $3(6.67)$ & $1(2.22)$ & $2(4.00)$ & $2(4.00)$ & $1(2.22)$ & $12(26.67)$ \\
\hline $\begin{array}{l}\text { Continuity } \\
\text { group }\end{array}$ & 45 & $1(2.22)$ & $1(2.22)$ & $0(0.00)$ & $1(2.22)$ & $1(2.22)$ & $0(0.00)$ & $4(8.89)^{*}$ \\
\hline$X^{2}$ & & & & & & & & 8.890 \\
\hline$P$ & & & & & & & & 0.003 \\
\hline
\end{tabular}

${ }^{*}$ Compared with routine group $\mathrm{p}<0.05$

routine group, and the improvement time of clinical hypothermia, cough, shortness of breath and rales in the continuous group is lower than that in the routine group. It is suggested that continuous nursing can improve the clinical effect and treatment efficiency of children. It can be concluded that continuous nursing can improve the eating habits, eat less and eat more times, increase the intake of protein, improve the body quality of children, relieve the anxiety and other emotions of children and their families through psychological intervention, guide their families to understand the knowledge and precautions of pneumonia prevention, adopt the correct expectoration method, and speed up the improvement of the condition, which is consistent with the research results of Liang et al..$^{[10,11]}$. Continuous nursing is a new type of nursing method gradually used in recent years. It is not only a nursing method to intervene the life and condition of children in hospital and after discharge, but also to change unreasonable nursing methods and concepts with children as the core, which is suitable for the clinical application under the changing predictive model ${ }^{[12]}$. He et al..$^{[13,14]}$ found that continuous nursing was adopted for 3-5 y old children with pneumonia, the clinical improvement rate of patients increased, the discharge time of patients accelerated, and many kinds of adverse events caused by incomplete treatment were reduced through out of hospital guidance.

This study found that the quality of life, nursing satisfaction and the improvement of complications in the continuity group were better than those in the routine group. This shows that continuous nursing can improve the quality of life of children from multiple perspectives. The quality of life is a recognized health state, and children with pneumonia will increase their psychological pressure due to the restlessness and anxiety caused by pain ${ }^{[15]}$. Parpa et al..$^{[16]}$ found that continuous nursing can reduce children's bad mood, communicate treatment plan with children's families, and increase children's immune function, antibacterial virus infection ability and living condition through diet and proper exercise, which is consistent with those reported by Jamil et al. ${ }^{[17,18]}$.

Continuous nursing to meet the needs of patients, improve the overall level of nursing, improve patient satisfaction, promote more effective nursing work, and promote the improvement of doctor-patient relationship. Yang et al.${ }^{[19]}$ found that continuous nursing can improve the nursing satisfaction of children with pneumonia and reduce medical disputes. The continuous nursing process continues outside the hospital, urging the children to adhere to the nursing content and carry out rehabilitation training, which has a good effect on the growth and development of the patients and the improvement of the body immunity, while reducing the occurrence of complications, which is similar to the research of Zheng ${ }^{[20]}$. To sum up, continuous nursing helps children with pneumonia to improve recovery, reduce pain time, reduce medical disputes, reduce heart, muscle and lung failure and is worthy of application.

\section{Conflict of interest:}

No conflict of interest between any of the authors.

\section{Acknowledgement:}

This study was supported by Project of Hengshui City of Hebei Province, named 'Analysis of correlation factors in children with refractory Mycoplasma pneumonia (20160140942).

\section{REFERENCES}

1. Li HN, Liu J, Zhao X. Analysis of pathogenic characteristics and related factors of nosocomial infection in children with refractory Mycoplasma pneumoniae pneumonia. Chin J Nosoco Infec 2018;28:273-5.

2. Chen XY, Lai M. Effect of immunoglobulin combined with methylprednisolone on immune function of children with severe Mycoplasma pneumonia. Mat Child Health Care Chin 2017;32:305-7.

3. Xin XY, Geng Y, Li XH. Effect of continuous nursing on mental health and self-care ability of elderly patients with chronic obstructive pulmonary disease. Int J Chron Obstruct Pulmon Dis 2018;27:4091-4.

4. Razmjoee N, Ebadi A, Asadi-Lari M, Hosseini M. Does a 
"continuous care model" affect the quality of life of patients undergoing coronary artery bypass grafting. J Vasc Nurs 2017;35:21-6.

5. Lou LF, Li XB, Zhang LQ. Analysis of the changes of serum immunoglobulin, erythrocyte immunity and peripheral blood T lymphocyte subsets after Mycoplasma pneumoniae infection in children. Mat Child Health Care Chin 2015;30:385-7.

6. Fang XL, Li XX, Lin Y. Analysis of risk factors of secondary diarrhea in children with pneumonia and comprehensive nursing. J Wan Med Col 2016;35:297-300.

7. Wang L, Ma RW. The effect of individualized nursing intervention on children with Mycoplasma pneumoniae infection. Nurs Res 2017;31:1143-5.

8. Jiang JS, Xing M, Gan S, San HJ. In the treatment of 58 cases of viral pneumonia in children. J Prac Clin Med 2015;19:1323.

9. Lv LS. Effect of continuous nursing on patients with chronic pneumonia heart disease and its effect on nursing satisfaction. Cardiovas Dis Preven Cont Knowled 2018;19:79-81.

10. Liang HY, Wang YQ, Li HX. Observation on the clinical effect of health education plan mode in the nursing of children with severe pneumonia. Herb Med 2018;21:2862-5.

11. Khateeb DM, West FM. Palliative management and end-of-life care in non-malignant advanced lung disease. Clin Pulm Med 2017;24:206-14.

12. Kalra A. Care seeking and treatment related delay among childhood tuberculosis patients in Delhi, India. Int $\mathrm{J}$ Tuberc Lung Dis 2017;21:645-50.

13. He YS, Zhao HJ. The effect of continuous nursing on the publication and quality of life of pneumonia in children with non-operative congenital heart disease. Lingnan Modern Clin Surg 2015;15:760-2.

14. Liu D, Liu LN, Hua K. Application status and development trend of multidisciplinary team cooperation in continuous nursing of children with severe pneumonia. Integ Nurs Trad Chin West Med 2019;5:197-200.

15. Li SL, Wang YH. The effect of continuous nursing in the home care of preschool children with asthma. Shang Nurs 2016; 16:49-51.

16. Parpa E, Galanopoulou N, Tsilika E. Psychometric properties of the patients' satisfaction instrument FAMCARE-P13 in a palliative care unit. Am J Hosp Palliat Care 2017;34:597-602.

17. Jamil KS, Sayed EKME. Social support as a mediator variable of the relationship between depression and life satisfaction in a sample of Saudi caregivers of patients with Alzheimer's disease. Intl Psychoger 2017;29:239-48.

18. Chen LX, Xu H. The effect of continuous nursing intervention on children and their parents with recurrent respiratory tract infection. Chin Med J 2018;1:159-62.

19. Yang WQ, Yao W, Zhang BB. Application of wechat public platform in continuous nursing of children with atopic dermatitis. J PLA Nurs 2018;35:49-52.

20. Zheng YX. Effect of continuous nursing intervention on selfcare ability and quality of life of elderly patients with recurrent respiratory tract infection. J Prac Clin Med 2017;21:50-2.

This is an open access article distributed under the terms of the Creative Commons Attribution-NonCommercial-ShareAlike 3.0 License, which allows others to remix, tweak, and build upon the work non-commercially, as long as the author is credited and the new creations are licensed under the identical terms

This article was originally published in a special issue, "Recent Trends in Biomedical Research" Indian J Pharm Sci 2020:82(1)spl issue 1; XX-XX 